\title{
Experimental and numerical evaluations of the energy savings potential of thermally anisotropic composites
}

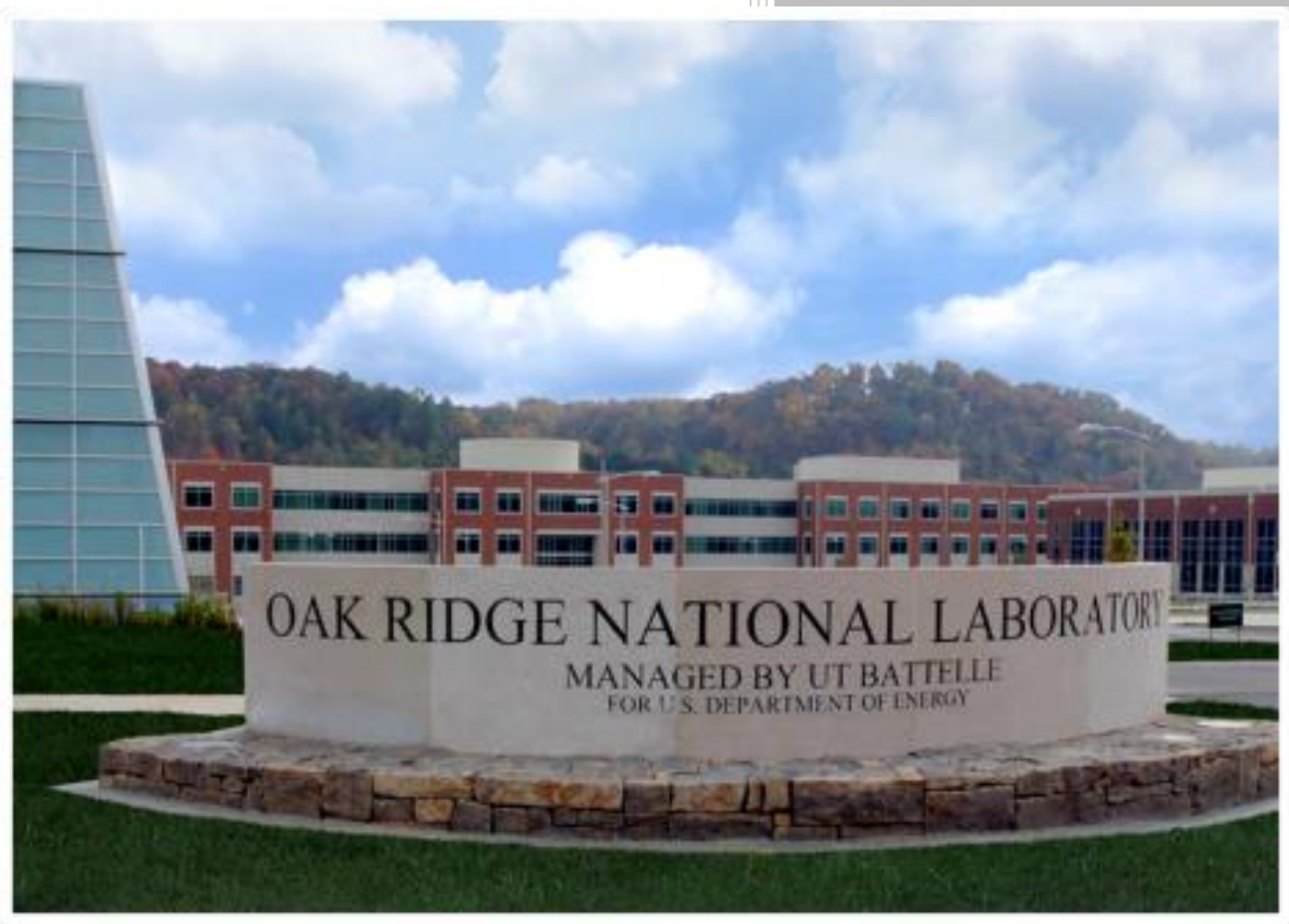

Approved for public release.

Kaushik Biswas, PhD Som Shrestha, PhD Diana Hun, PhD Jerald Atchley

Distribution is unlimited.

May 2019 


\title{
DOCUMENT AVAILABILITY
}

Reports produced after January 1, 1996, are generally available free via US Department of Energy (DOE) SciTech Connect.

Website http://www.osti.gov/scitech/

Reports produced before January 1, 1996, may be purchased by members of the public from the following source:

\author{
National Technical Information Service \\ 5285 Port Royal Road \\ Springfield, VA 22161 \\ Telephone 703-605-6000 (1-800-553-6847) \\ TDD 703-487-4639 \\ Fax 703-605-6900 \\ E-mail info@ntis.gov \\ Website http://www.ntis.gov/help/ordermethods.aspx
}

Reports are available to DOE employees, DOE contractors, Energy Technology Data Exchange representatives, and International Nuclear Information System representatives from the following source:

Office of Scientific and Technical Information

PO Box 62

Oak Ridge, TN 37831

Telephone 865-576-8401

Fax 865-576-5728

E-mail reports@osti.gov

Website http://www.osti.gov/contact.html

This report was prepared as an account of work sponsored by an agency of the United States Government. Neither the United States Government nor any agency thereof, nor any of their employees, makes any warranty, express or implied, or assumes any legal liability or responsibility for the accuracy, completeness, or usefulness of any information, apparatus, product, or process disclosed, or represents that its use would not infringe privately owned rights. Reference herein to any specific commercial product, process, or service by trade name, trademark, manufacturer, or otherwise, does not necessarily constitute or imply its endorsement, recommendation, or favoring by the United States Government or any agency thereof. The views and opinions of authors expressed herein do not necessarily state or reflect those of the United States Government or any agency thereof. 


\title{
Energy and Transportation Science Division
}

\section{Experimental and numerical evaluations of the energy savings potential of thermally anisotropic composites}

\author{
Kaushik Biswas, PhD \\ Som Shrestha, PhD \\ Diana Hun, PhD \\ Jerald Atchley
}

Date Published:

May 2019

Prepared by

OAK RIDGE NATIONAL LABORATORY

Oak Ridge, TN 37831-6283

managed by

UT-BATTELLE, LLC

for the

US DEPARTMENT OF ENERGY

under contract DE-AC05-00OR22725 


\section{INTRODUCTION}

Previous numerical studies conducted in FY 17 showed that the application of thermally anisotropic composites (TACs) coupled with a heat sink/source can re-direct and reduce unwanted heat flows through exterior building walls, with associated reductions in envelope-generated heating and cooling loads in buildings [1]. The numerical analyses included two-dimensional finite element models (FEM) of wall assemblies and whole-building modeling to estimate the annual reductions in wall-generated heating and cooling loads, and associated energy consumption. The FY17 study used combined FEM and EnergyPlus $\left(\mathrm{E}_{+}\right)$simulations of a typical two-story, single-family DOE prototype residential building model. ${ }^{1}$ We studied performance of several configurations of walls containing exterior continuous insulation and thermally anisotropic composites on the wall exterior. The study showed that annual energy cost savings of up to $\$ 270$ are possible under Phoenix and Baltimore weather conditions, by retrofitting a baseline wall with an anisotropic composite. In the cases considered, the TAC consisted of three layers of aluminum foil-faced foam boards. In general, it was found that the anisotropic composites were effective in reducing cooling loads; more investigation on heating loads is needed.

During FY 18, ORNL performed a series of laboratory tests of anisotropic composites and appropriate heat sink/source, validated the FEMs used for the FY17 numerical study using experimental data, and revisited the whole-building modeling. Wall prototypes were created and tested in ORNL's large scale climate simulator (LSCS) under variable conditions approximating summer and winter time periods.

\section{PROTOTYPE WALLS AND TEST CONDITIONS}

For experimental verification of the anisotropic concept, some small-scale tests were done in a heat flow meter (HFM) apparatus. Figure 1 shows the anisotropic composite-heat sink configuration. The TAC consisted of three alternating layers of Al foil and 0.25 " extruded polystyrene (XPS) foam sheets, and was sandwiched by 0.5 " gypsum sheets above and below.

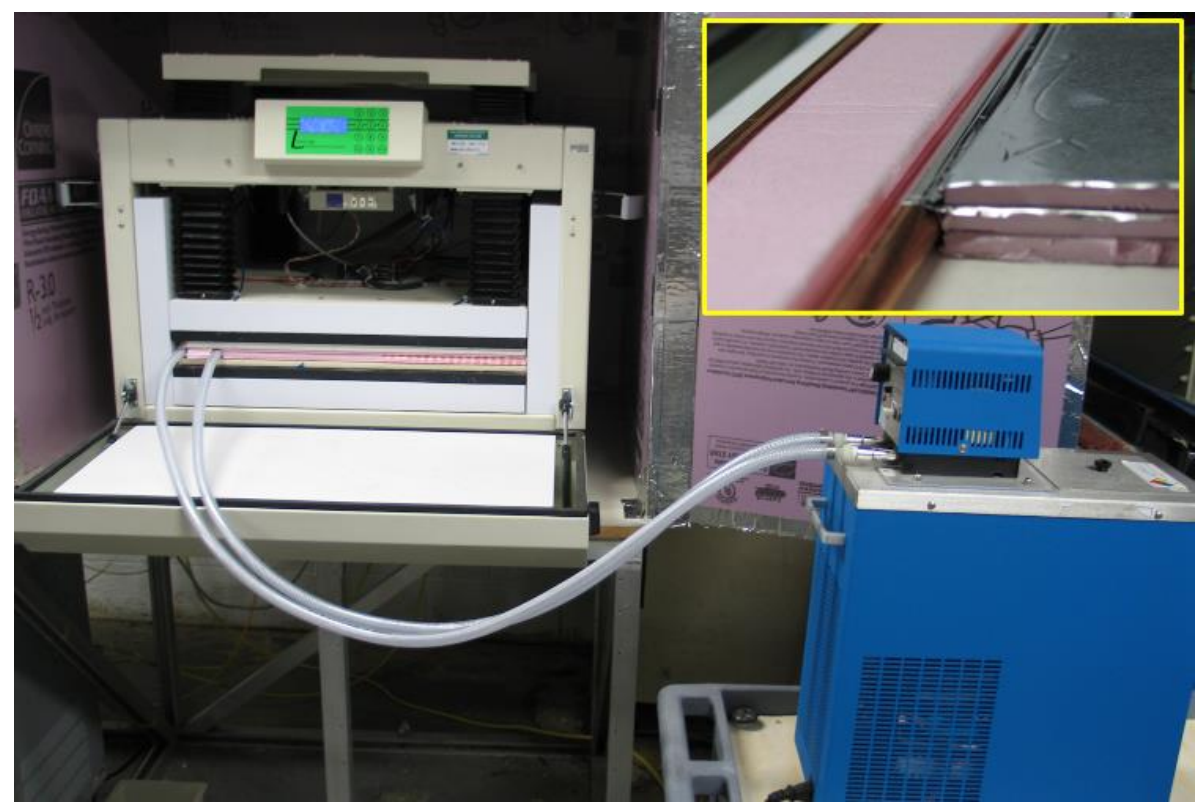

Figure 1. Small-scale anisotropic sample in an HFM; Inset - TAC consisting of alternating layers of XPS sheet and Al foil ( 3 each) connected to a copper tube with circulating water acting as the heat sink.

\footnotetext{
${ }^{1}$ https://www.energycodes.gov/development/residential/iecc models
} 


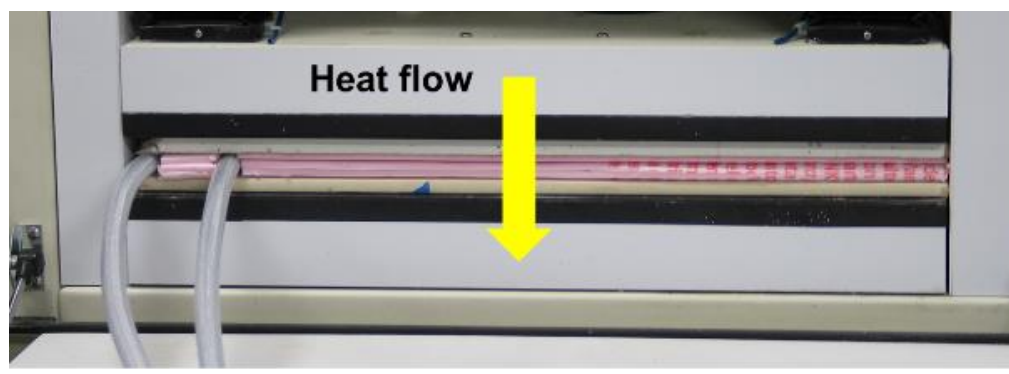

\section{No water circulation}

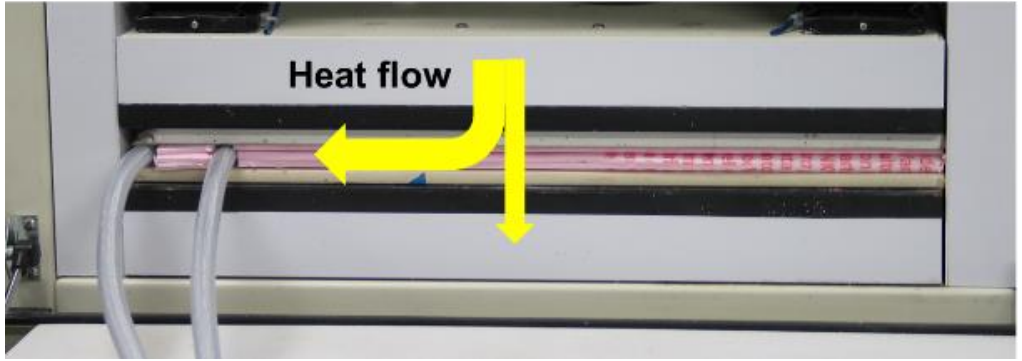

\section{With water}

circulation

Figure 2. Impact of anisotropic composite and heat sink on the heat flow.

Figure 2 illustrates the expected impact of the anisotropic composite and the heat sink (tube with circulating water) on the heat flow between the two plates of the HFM when the water circulation was turned off and on. Two tests were performed, the first with the Al foil layers and the second test was done after removing the Al foil layers. The HFM contains an array 15 heat flux transducers in each plate to measure the heat flows through different regions of tested samples. Figure 3 shows the relative locations of HFTs 5-8 in the HFM plates with respect to the TAC and the copper tube. HFT 5 was overlapping one segment of the copper tube, while HFTs 6-8 were away from the copper tube. The tests were run for multiple hours and the water circulation was turned on and off during the test periods.

Next, full-scale wood-framed wall assemblies with and without exterior continuous insulation and the anisotropic composite(s) were built and tested in the LSCS. The metering area of the test walls was $8^{\prime} \times 8^{\prime}$

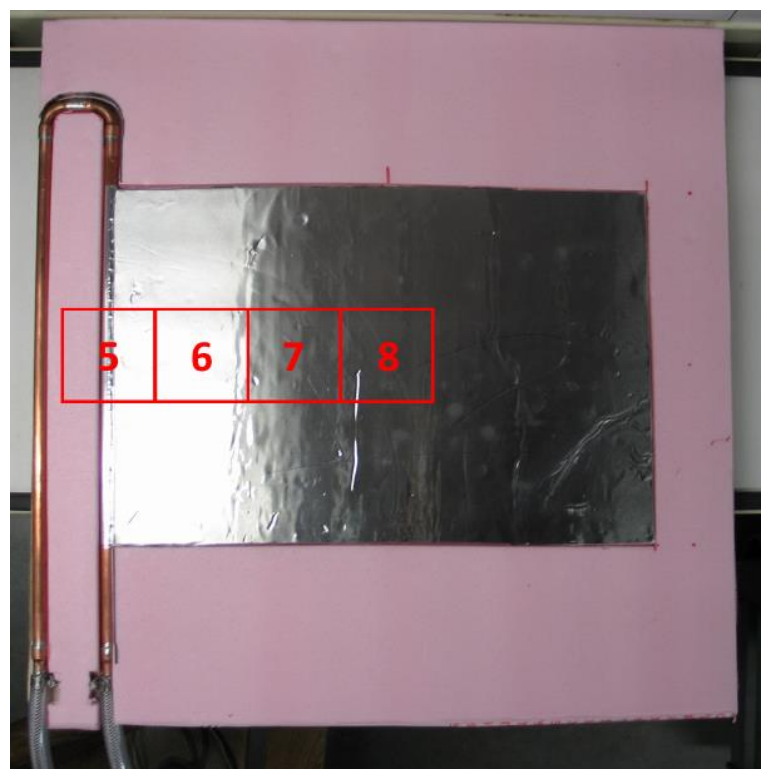

Figure 3. Relative locations of HFTs with respect to the copper tube.

in dimensions. The primary baseline wall consisted of 16 inch on center (o. c.) $2 \times 4$ wood frame construction, with cavity insulation and sheathings on the exterior and interior sides. A second baseline consisted of three layers of 0.5 " XPS added as exterior continuous insulation (Cl). Finally, the third wall configuration included TACs consisting of three layers of 0.5 " XPS with aluminum facings or foils. The wall with the anisotropic composites also contained heat exchanger pipes using water flow to and from water baths, which acted as the heat source and sink.

As shown in Figure 4, the LSCS consists of three chambers - climate, metering and guard chambers. The climate chamber simulates outdoor weather conditions; temperature, humidity, solar irradiance, and wind speed. It can maintain steady conditions or simulate diurnal weather conditions. The exterior side of the wall assembly is exposed to the climate chamber. The lower portion of the LSCS contains a guard 
chamber and a metering chamber. The metering chamber is surrounded by the guard chamber on five sides, except the side facing up, which is exposed to the test specimen. The metering and guard chambers simulate indoor temperature and humidity. The LSCS serves as a guarded hot box apparatus. The tests will be conducted in accordance with ASTM C1363-11 "Standard Test Method for Thermal Performance of Building Materials and Envelope Assemblies by Means of a Hot Box Apparatus."

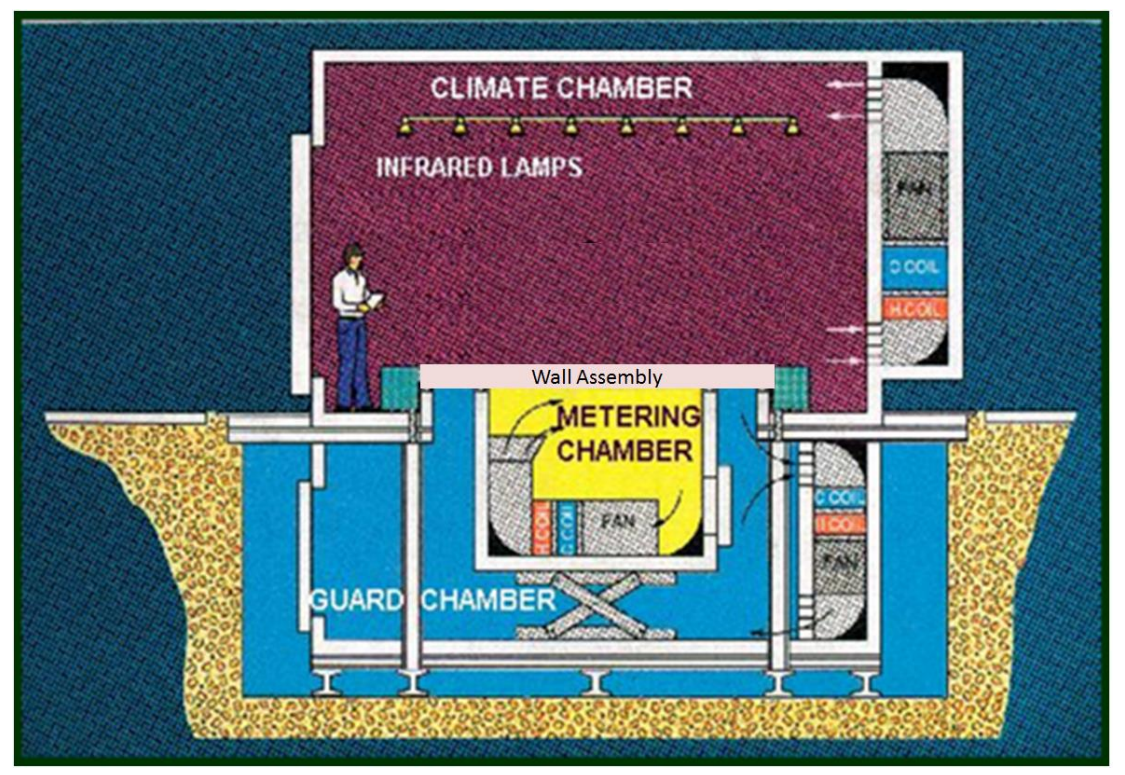

Figure 4. Sketch of the large scale climate simulator (LSCS)

The test specimen, the wall assemblies in this case, is typically supported at the open end of guard and meter chambers, so its "exterior" surface is exposed to the climate chamber and its "interior" surface is exposed to the meter chamber. The metering chamber can be raised so that it seals against the indoor side of the wall assembly and provides a measurement of the total heat flow through the 8 feet $(2.44 \mathrm{~m})$ by 8 feet $(2.44 \mathrm{~m})$ central area of the wall. The surrounding guard chamber temperature is maintained close to the metering chamber temperature to minimize heat flows across the metering chamber walls. Heat flow through the wall can then be calculated from an energy balance of the metering chamber, i.e. the heat input or removal from the meter chamber to maintain the "indoor" temperature.

The following walls were tested in the LSCS:

1. Baseline: 0.5 " gypsum board facing the meter (indoor) chamber, $2 \times 4$ studs with nominal R-13 fiberglass insulation, and 0.5 " OSB facing the climate chamber.

2. Baseline + XPS: Three layers of 0.5 " XPS foam boards were added as exterior continuous insulation to the baseline wall.

3. Baseline + TAC: Three alternating layers of 0.5 " XPS and 0.005 " aluminum foil were added to the baseline wall. The XPS-AI layers acted as the thermally anisotropic composite (TAC).

a. Also added to this wall were three copper tubes as water lines which were used as the heat sink/source. The Al foil sheets were wrapped around the water lines.

Figure 5 shows the water lines used as the sink or source in the anisotropic wall system and Figure 6 shows the TAC with the Al foil connected to the copper tubes. 


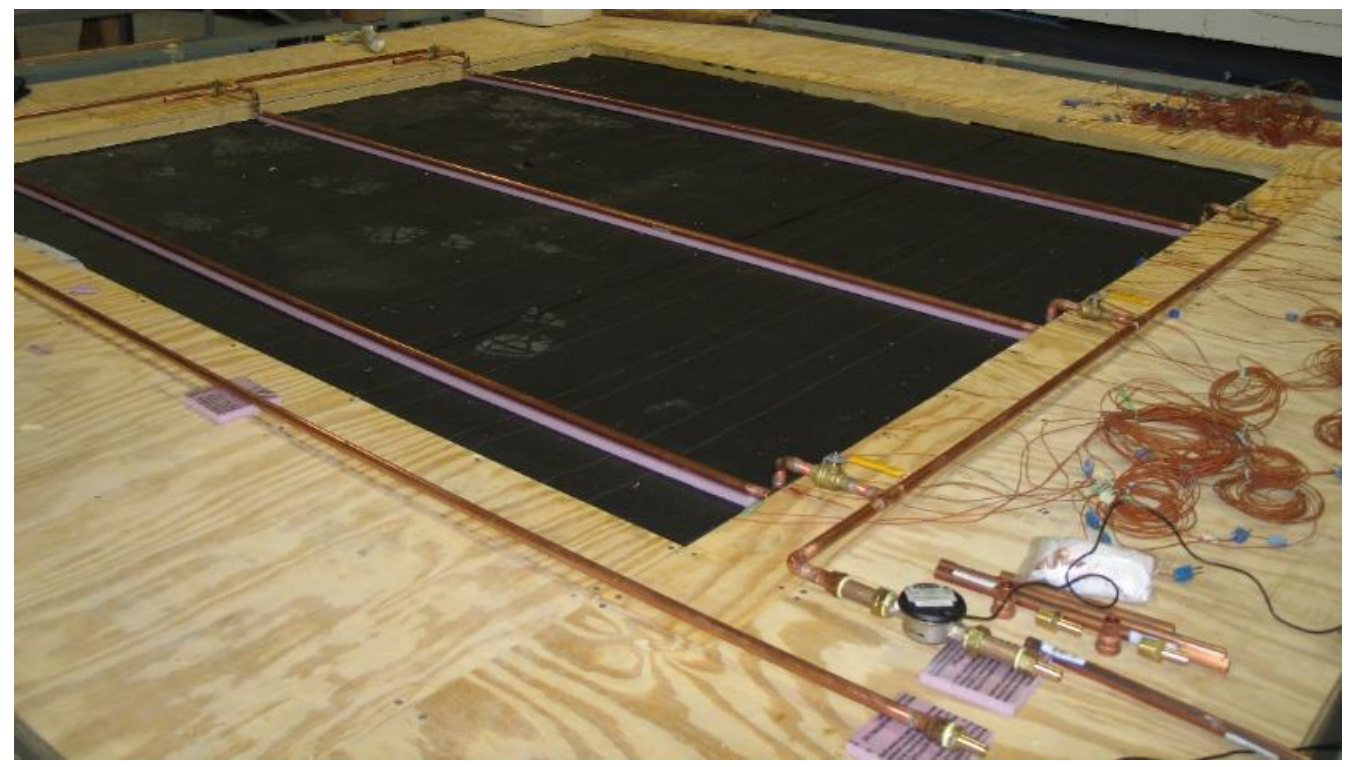

Figure 5. Copper tubes (3) with circulating water used as heat sink or source.
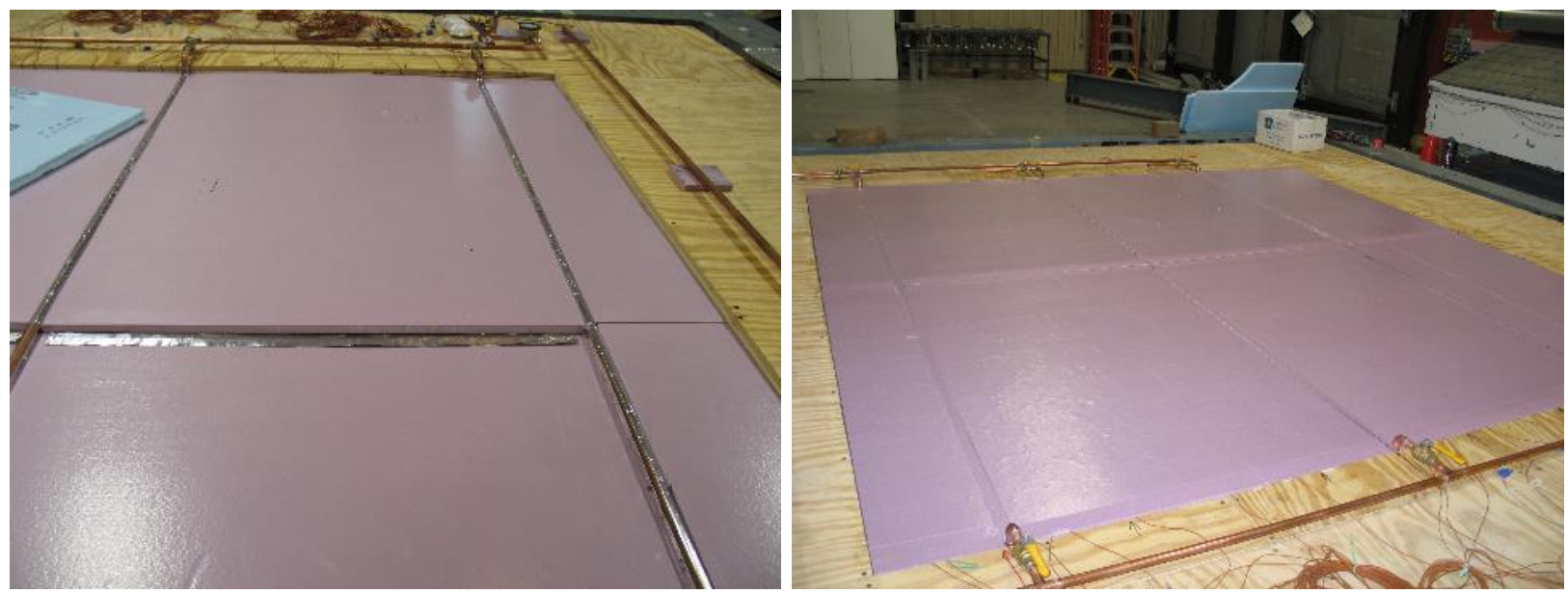

Figure 6. TAC containing alternating layers of 0.5 " XPS and 0.005 " Al foil connected to the copper tubes.

\section{RESULTS AND DISCUSSION}

Small-scale HFM Tests: In these tests, the upper plate was set at $40^{\circ} \mathrm{C}$, the lower plate was set at $10^{\circ} \mathrm{C}$ and the circulating water chiller temperature was $5^{\circ} \mathrm{C}$. Figure 7 shows the temporal evolution of the measured heat flows by HFTs 5-8 in the top and bottom plates. The timing and duration of the water circulation being turned on and off are also shown. The impact of turning the water circulation on and off on the measured heat flows are clearly observable. When the water circulation was turned on, the copper tube acted as a heat sink providing directional heat dissipation due to the high thermal conductivity of the Al foil layers that are connected to the tube. The heat flow in the upper plate increased when the water circulation is turned on to compensate for heat removal by the circulating water and maintain the plate temperature at $40^{\circ} \mathrm{C}$. Conversely, the heat flow in the lower plate decreased due to the heat dissipation to the circulating water. Also noticeable is the impact on the HFTs based on their location. HFT 5, which overlaps the copper tube, saw the highest increase or decrease in heat flow when the water circulation is turned on. The magnitude of the change in heat flow progressively decreased with the distance of the HFT from the copper tube (i.e. HFT $6>7>8$ ). 

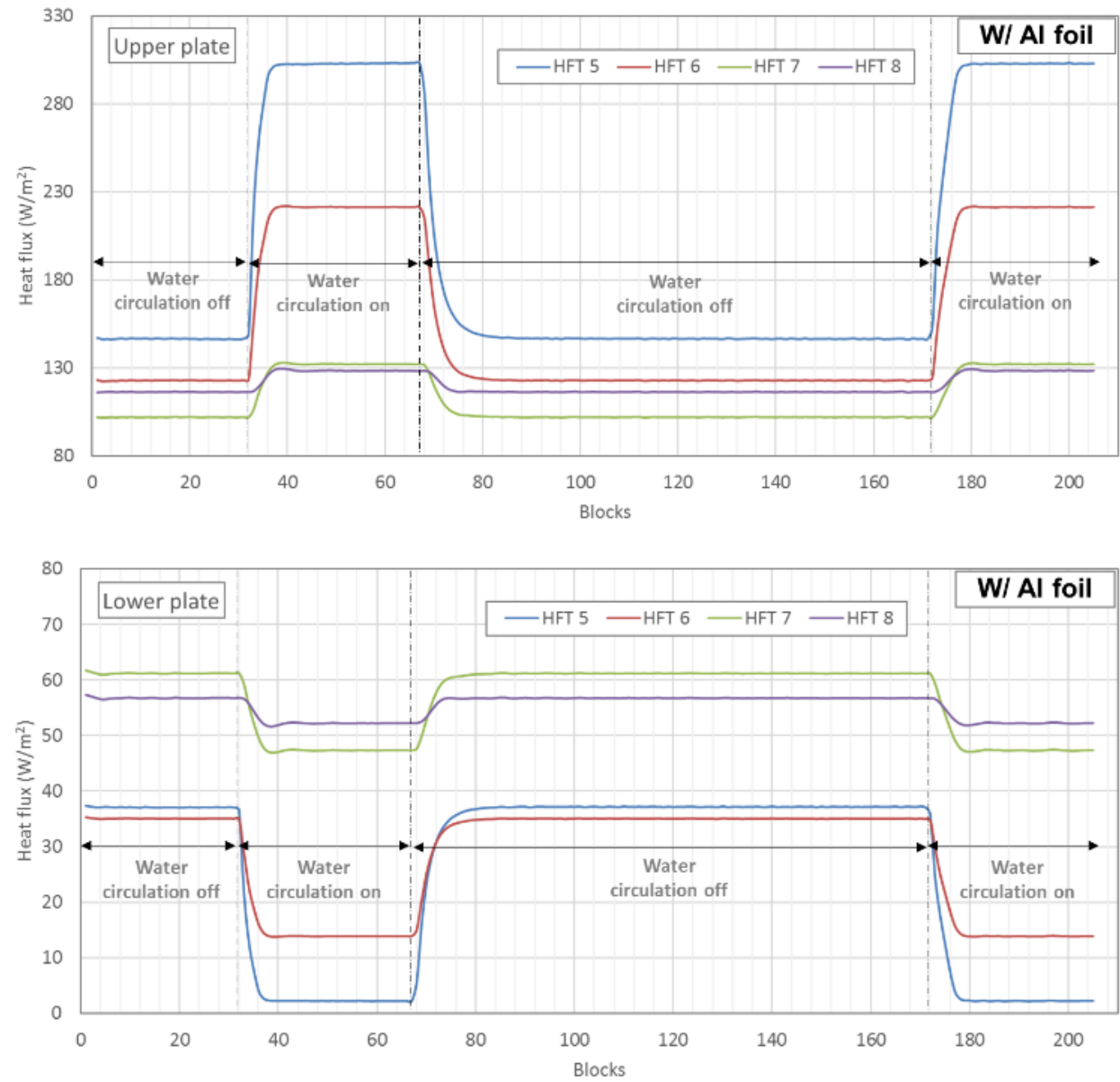

Figure 7. Heat flow measurements from the HFTs 5-8 in the upper and lower plates from the test with the Al foil layers.

Next, the test was repeated but without the Al foil layers. Figure 8 shows the evolution of HFTs 5-8 with the water circulation turned on and off. HFT 5 still showed a significant increase or decrease in the heat flow, since it overlaps the copper tube. However, HFTs 6-8 did not show any discernible increase or decrease in the measured heat flow. Thus, directional heat dissipation can be achieved with a combination of an anisotropic composite and a heat sink, but both thermal anisotropy and a heat sink (such as circulating water) are required.

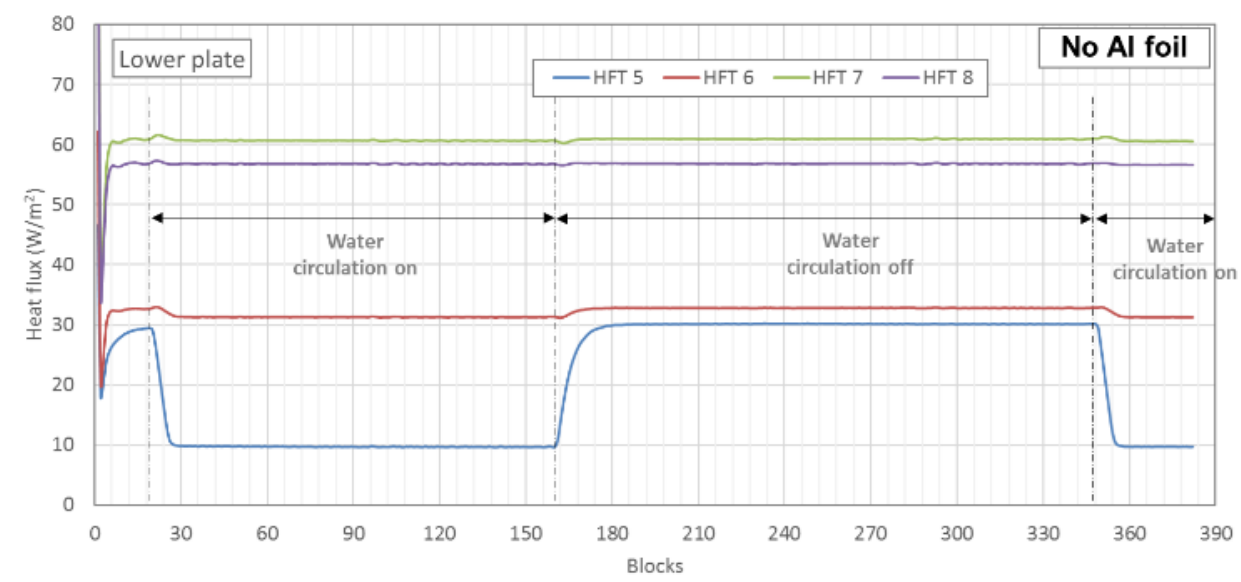




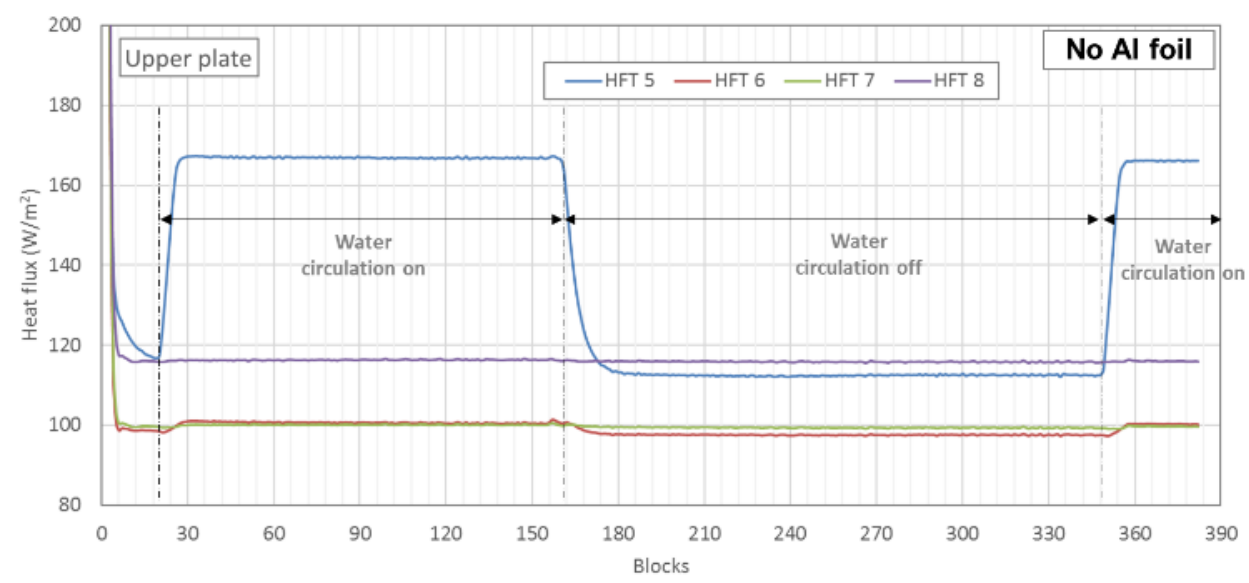

Figure 8. Heat flow measurements from the HFTs 5-8 in the upper and lower plates from the test without the Al foil layers.

Full-scale LSCS Tests: Figure 9 and Figure 10 compare the test parameters of the three walls that were tested under simulated summer and winter conditions. ' $C C$ ' is the climate chamber simulating outdoor conditions and ' $\mathrm{MC}$ ' is the meter chamber simulating room conditions. 'IRR' is the infrared radiation that is incident on the exterior wall surface facing the climate chamber. 'CC2MC Heat Flow' is the net heat transfer between the climate and meter chambers, through the test wall specimen; positive values represent net heat addition to the meter chamber. Reduction in the net heat transfer between the climate and meter chambers proves the efficacy of the proposed TAC with heat sink/source concept.

All tests were performed over multiple diurnal cycles. To the extent possible, similar cyclic summer and winter conditions were utilized for the different tests, but some differences were observed. For example, during the summer tests, the peak CC air temperatures were lower during the 'Base + TAC' test but the IRR was higher. Even considering the differences in the test conditions, significant reductions in heat gains and losses under summer and winter conditions, respectively, were observed with the 'Base + XPS' and 'Base + TAC' scenarios. For the 'Base + TAC' scenarios, the average circulating water temperatures were about $82^{\circ} \mathrm{F}$ under summer conditions and $69^{\circ} \mathrm{F}$ under winter conditions; these temperatures were chosen to be near ambient or to simulate ground temperatures. The water flow rate was about 10 liters per minute in both cases.
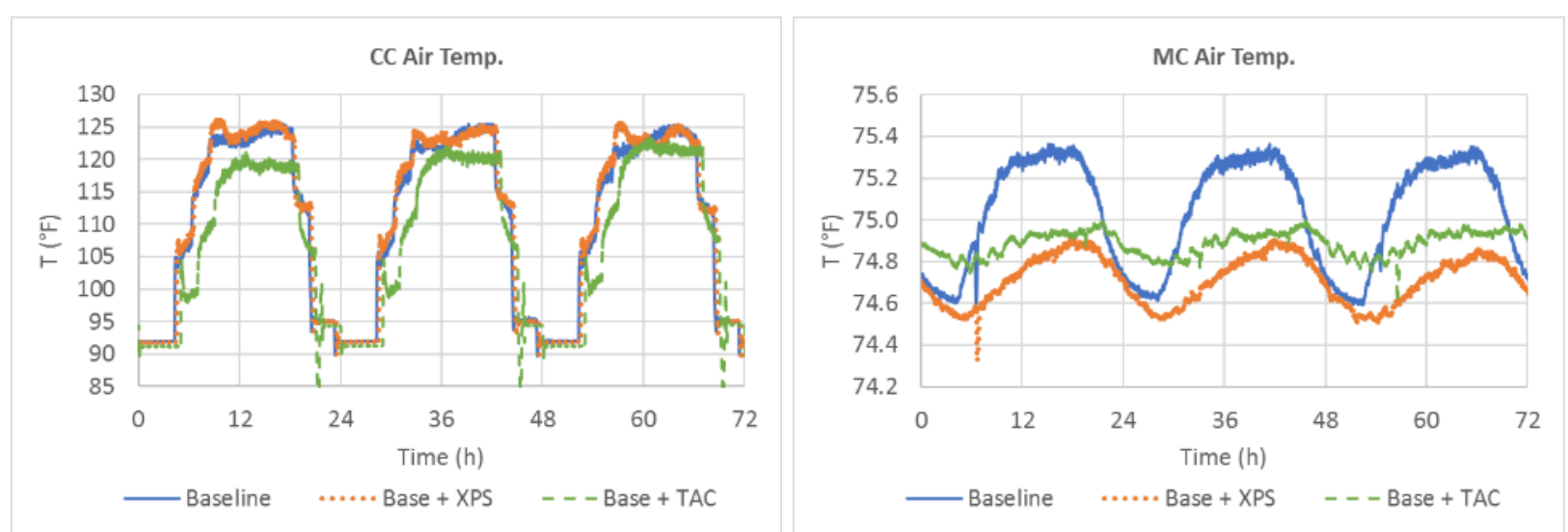

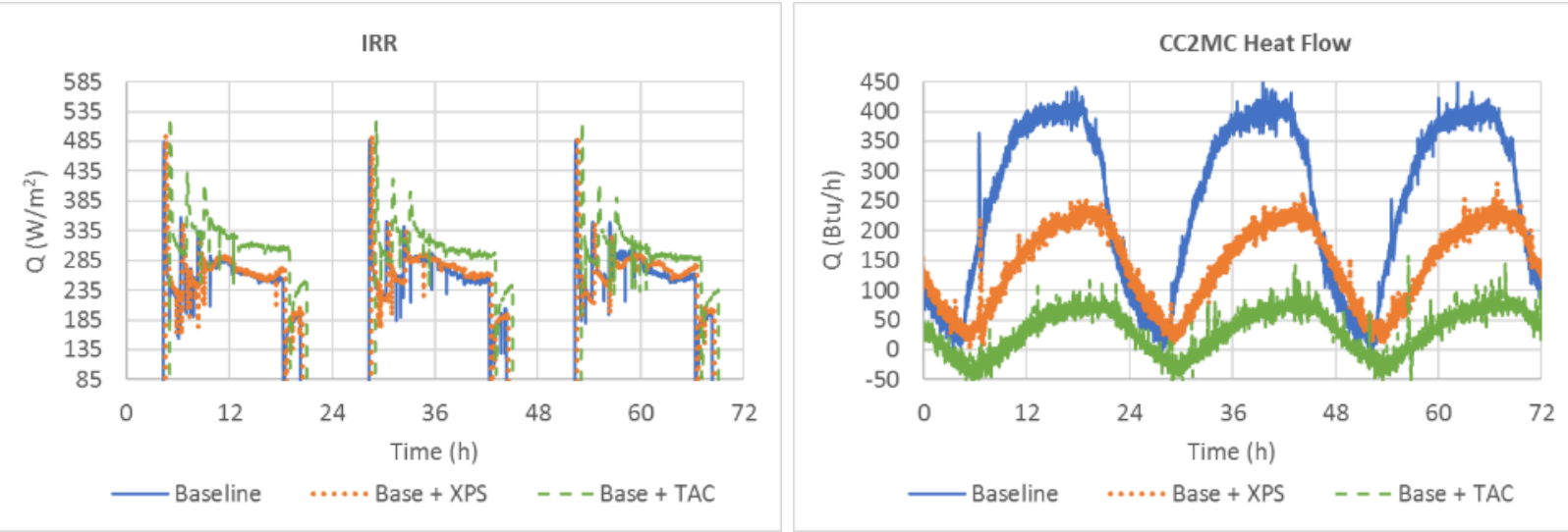

Figure 9. LSCS test parameters and measured heat flow under simulated summer conditions
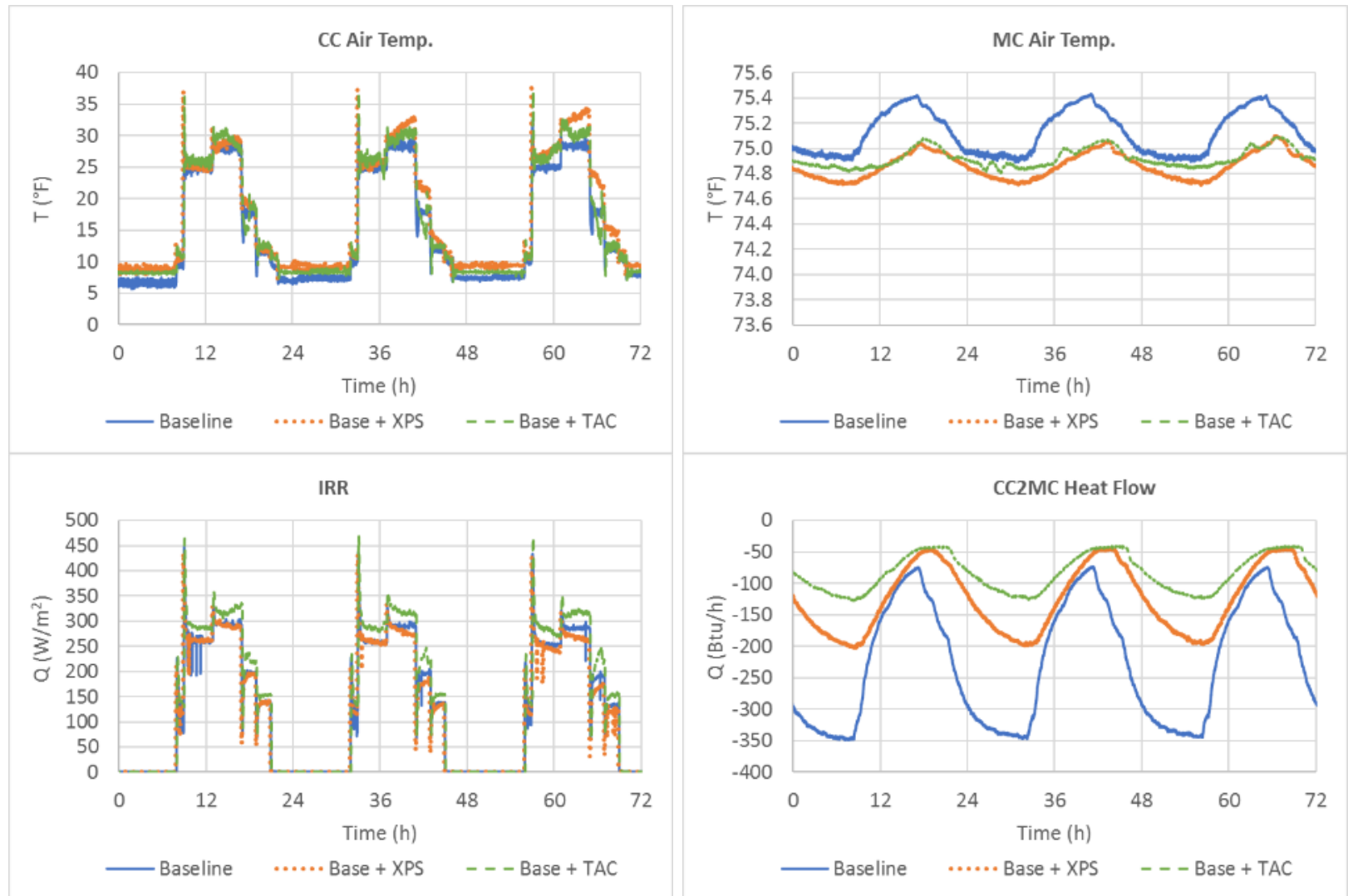

Figure 10. LSCS test parameters and measured heat flow under simulated winter conditions

Table 1 compares the net heat gains and losses under summer and winter conditions. Both 1.5" XPS and the TAC system significantly reduced the unwanted heat gains and losses, but the TAC system outperformed the 1.5 " XPS by $75 \%$ under summer conditions and $33 \%$ under winter conditions. However, future evaluations will need to include the energy consumption related to water circulation.

Table 1. Comparison of net heat flows between climate and meter chambers

\begin{tabular}{|c|c|c|c|c|}
\hline Test wall & $\begin{array}{c}\text { Heat Gain } \\
(\mathbf{k B t u} / \mathbf{h})\end{array}$ & $\%$ Diff. & $\begin{array}{c}\text { Heat Loss } \\
(\mathbf{k B t u} / \mathbf{h})\end{array}$ & $\%$ Diff. \\
\hline \multicolumn{5}{|c|}{ Summer } \\
\hline
\end{tabular}




\begin{tabular}{|l|r|r|r|r|}
\hline Baseline & 2174.32 & & -0.02 & \\
\hline Base + XPS & 1236.87 & $-43 \%$ & 0.00 & \\
\hline Base +TAC & 315.09 & $-86 \%$ & -39.24 & \\
\hline \multicolumn{5}{|c|}{ Winter } \\
\hline Baseline & 0.00 & & -1957.68 & \\
\hline Base + XPS & 0.00 & & -1076.38 & $-45 \%$ \\
\hline Base +TAC & 0.00 & & -720.65 & $-63 \%$ \\
\hline
\end{tabular}

Finite Element Model Validation: Two-dimensional COMSOL model geometries were created to match the cross-sections of the test walls and utilized appropriate materials properties based on the wall configurations. The COMSOL simulations were performed using the transient summer and winter test data from the LSCS. The measured surface temperatures on the exterior (climate-facing) wall surface and the meter chamber air temperatures were used as boundary conditions in the COMSOL simulations.

Figure 11 shows the comparison of the measured (LSCS) and calculated (COM.) heat flows from the climate to meter chambers under the different scenarios. Excellent agreement was observed between the measurements and calculations for the baseline and 'baseline + XPS'. The measurements and calculations in the 'baseline + TAC' cases did not agree as well as the previous scenarios, but the calculation results are deemed reasonable.
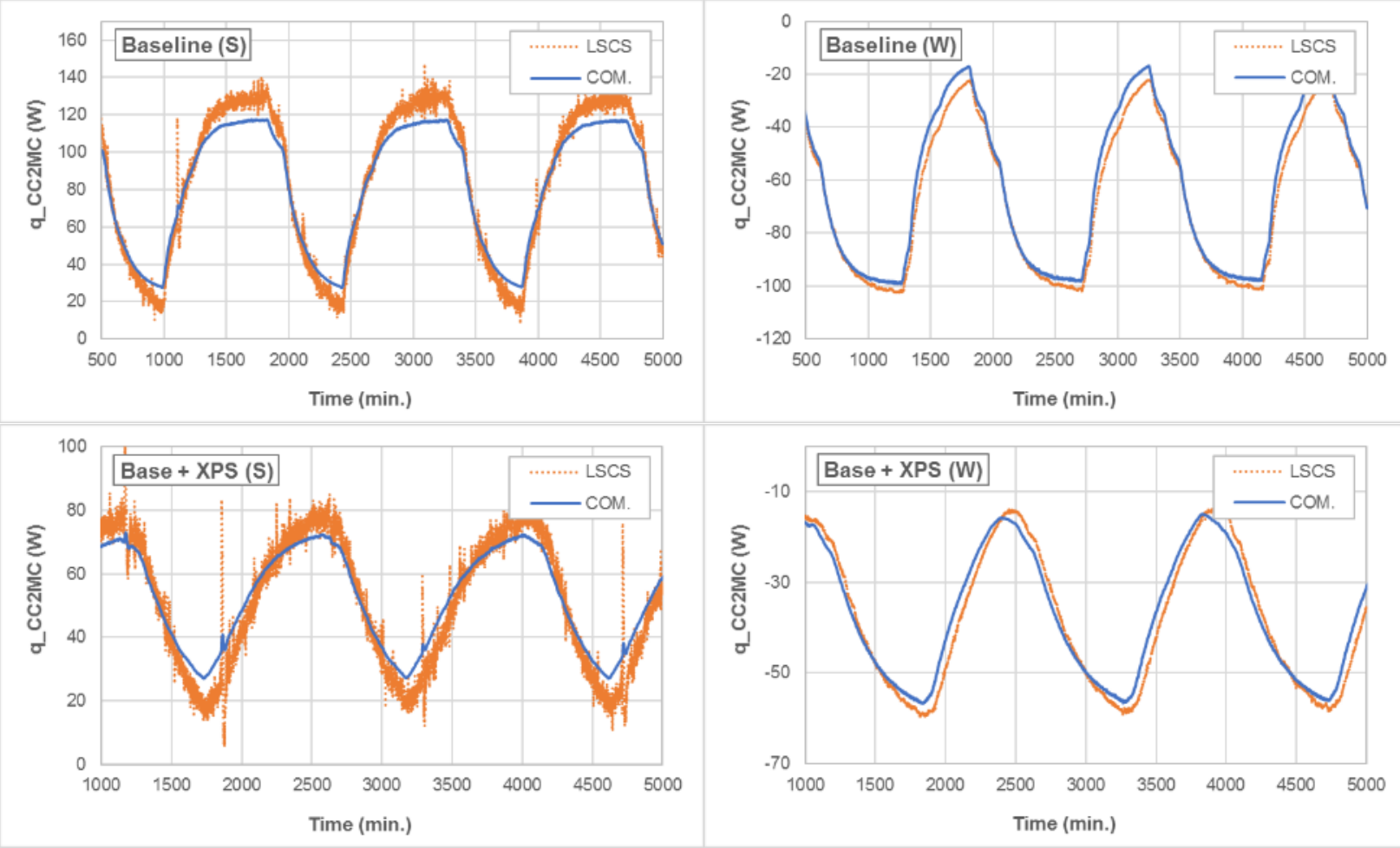

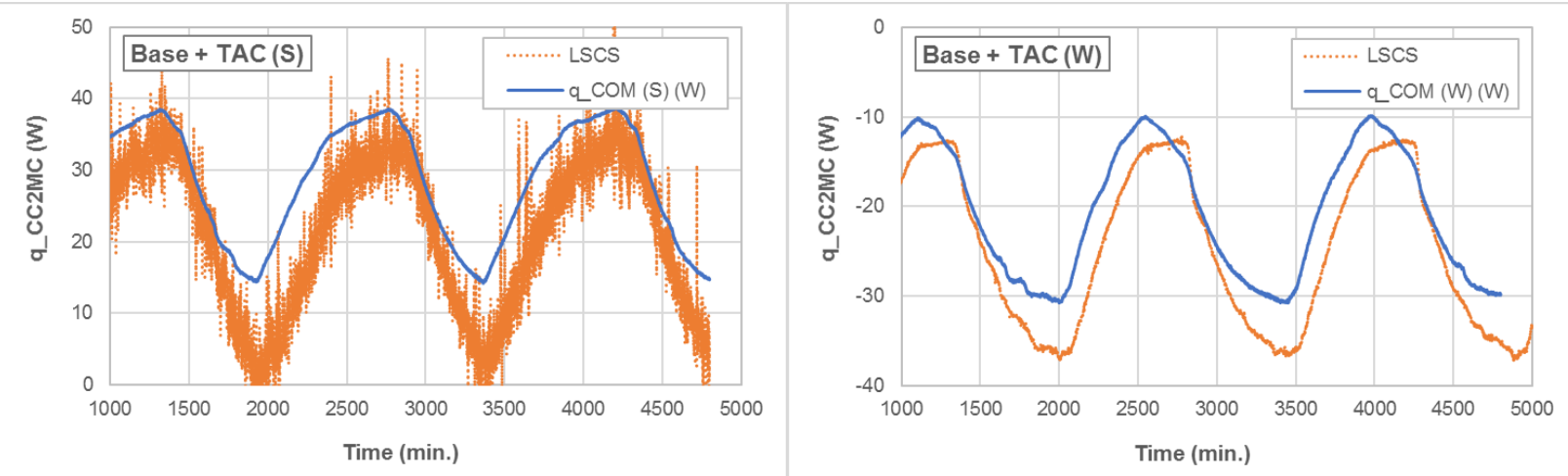

Figure 11. Comparison of measured and calculated heat flows from the climate to meter chamber (CC2MC). Plots on the left show results under summer conditions and those on the right show results under winter conditions.

Annual Energy Simulations: Next, annual simulations were performed using COMSOL and E+ using typical climate conditions for Phoenix, AZ and Baltimore, MD. The modeling process was the same as that reported in the FY17 technical assessment report [1] and is briefly described here. The first step was to build an E+ baseline whole building model, based on a residential prototype building model developed for Department of Energy (DOE) Building Energy Codes Program. The building used for this analysis is a wood-framed (2x4), two-story single-family detached house with a total conditioned floor area of about $1900 \mathrm{ft}^{2}$ and compliant with the 2006 version of the International Energy Conservation Code (IECC). ${ }^{2}$

Figure 12 illustrates the overall modeling and analysis process. The process started with a baseline whole-building $\mathrm{E}+$ model that was simulated to generate the indoor and outdoor boundary conditions for the 2D COMSOL models. Next, the COMSOL models calculated the wall-generated heating and cooling loads from the baseline, 'baseline + XPS' and 'baseline + TAC' wall configurations. Finally, hourly heat flows between the walls and the indoor space calculated from COMSOL were fed into a modified $E_{+}$ models as internal loads. The $\mathrm{E}+$ models were modified to make the walls adiabatic and the COMSOLcalculated heat gains and losses were treated as cooling and heating loads, respectively. This was necessary as E+ utilizes conduction heat transfer calculations that are one-dimensional, but twodimensional heat transfer simulations are needed to evaluate the impact of TACs.

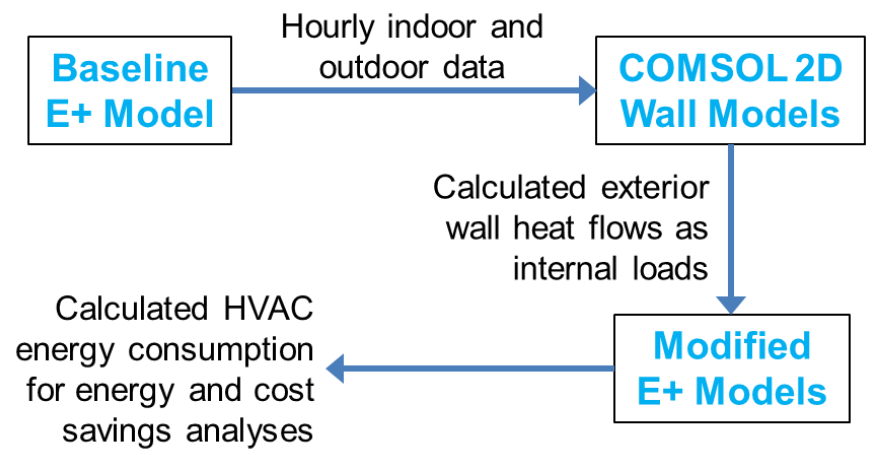

Figure 12. Flowchart illustrating the modeling and analysis process.

Figure 13 shows the COMSOL model geometry and materials related to the 'baseline + TAC' wall. The water lines were located in the middle of every alternate wall cavity in the LSCS test wall. Hence, the

${ }^{2}$ https://shop.iccsafe.org/codes/2018-international-codes-and-references/2018-international-energyconservation-code.html 
model domain contained the cavity with a heat sink/source and the adjacent cavities, assuming symmetry boundary conditions as shown in figure 13. The exterior wall surface was subjected to solar irradiance, convection heat transfer with the ambient environment, and radiation heat transfer with the surroundings, using typical weather conditions from Phoenix and Baltimore. The inside surface was subjected to convection and radiation heat transfer with the indoor air. The hourly boundary condition data were created using the baseline $\mathrm{E}+$ model.

The hourly heat flows at the interior surface were calculated and used as inputs to the modified $E_{+}$ models. In the 'baseline + TAC' model shown in figure 13, the Al layers in the TAC are highlighted by thick blue lines, which are connected to the small square marked as heat sink/source. The heat sink and source were switched based on outdoor conditions; at outdoor temperatures above $55^{\circ} \mathrm{F}$, a heat sink at $82^{\circ} \mathrm{F}$ was assumed and at temperatures below $55^{\circ} \mathrm{F}$, a heat source at $68^{\circ} \mathrm{F}$ was assumed. The heat sink and source temperatures were based on the measured average water flow temperatures in the summer and winter LSCS tests, respectively.

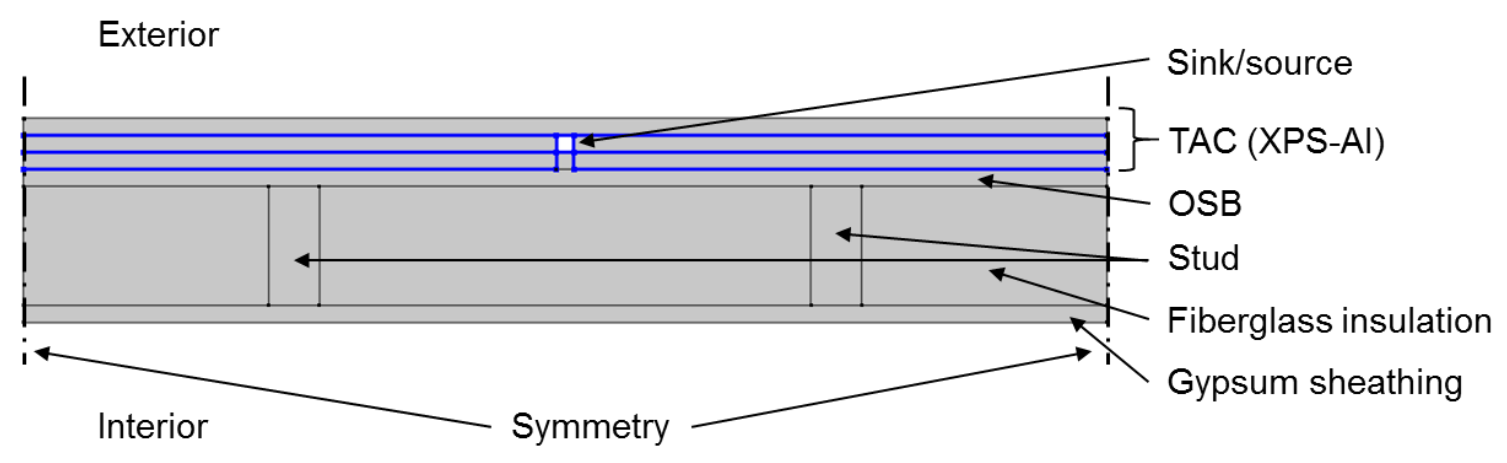

Figure 13. COMSOL model geometry representing the baseline + TAC scenario.

Table 2 summarizes the calculated whole-building HVAC energy consumption associated with the different wall configurations. The associated annual cost savings were also calculated and are listed in table 2. The energy costs are based on regional cost data from the Energy Information Administration (EIA) database. The cost of electricity for Phoenix and Baltimore were assumed to be $\$ 0.1278 / \mathrm{kWh}$ and $\$ 0.1348 / \mathrm{kWh}$, respectively, using averaged 2017 and 2018 data. $^{3}$ The cost of natural gas (in $\$ / 1000$ cubic feet) was 15.84 for Phoenix and 12.08 for Baltimore, using the latest 5-year averages from EIA database. ${ }^{4}$ One-thousand cubic feet of natural gas translates to 10.37 therm. ${ }^{5}$

Table 2. Comparison of E+ calculated annual HVAC energy consumption and associated cost savings

\begin{tabular}{|l|r|r|r|r|r|r|}
\hline $\begin{array}{c}\text { HVAC energy } \\
\text { use }\end{array}$ & $\begin{array}{c}\text { Electricity } \\
\text { (kWh) }\end{array}$ & \% Diff. & $\begin{array}{c}\text { Cost } \\
\text { saving (\$) }\end{array}$ & $\begin{array}{c}\text { Natural gas } \\
\text { (Therm) }\end{array}$ & \% Diff. & $\begin{array}{c}\text { Cost } \\
\text { saving (\$) }\end{array}$ \\
\hline \multicolumn{7}{|c|}{ Phoenix } \\
\hline Baseline & 11304 & & & 156.8 & & \\
\hline Baseline + XPS & 10323 & $-8.7 \%$ & $\$ 125$ & 123.3 & $-21.3 \%$ & $\$ 51$ \\
\hline Baseline + TAC & 9989 & $-11.6 \%$ & $\$ 168$ & 104.1 & $-33.6 \%$ & $\$ 80$ \\
\hline \multicolumn{7}{|c|}{ Baltimore } \\
\hline Baseline & 4124 & & & 749.3 & & \\
\hline
\end{tabular}

${ }^{3}$ https://www.eia.gov/electricity/monthly/epm table grapher.cfm?t=epmt 506 a

4 https://www.eia.gov/dnav/ng/ng pri sum a EPGO PRS DMcf a.htm

5 https://www.eia.gov/tools/faqs/faq.php?id=45\&t=8 


\begin{tabular}{|l|l|l|l|l|l|r|} 
Baseline + XPS & 3793.7 & $-8.0 \%$ & $\$ 45$ & 656.2 & $-12.4 \%$ & $\$ 108$ \\
\hline Baseline + TAC & 3832.3 & $-7.1 \%$ & $\$ 39$ & 582.5 & $-22.3 \%$ & $\$ 194$ \\
\hline
\end{tabular}

The total calculated annual cost savings for the XPS case were $\$ 176$ in Phoenix and $\$ 153$ in Baltimore; with TAC, the estimated cost savings were $\$ 248$ and $\$ 233$ in Phoenix and Baltimore, respectively. In order to calculate payback, estimates of the retrofit costs for the XPS and TAC cases are needed. A National Renewable Energy Laboratory (NREL) database lists the average costs of retrofitting residential walls with 1 and 2 inches of XPS insulation as $\$ 1.30 / \mathrm{ft}^{2}$ and $\$ 1.70 / \mathrm{ft}^{2}$, respectively. ${ }^{6}$ Assuming a mean cost of $\$ 1.50 / \mathrm{ft} 2$ for 1.5 " XPS, the total cost of retrofitting the walls of the modeled residential building is $\$ 2,899$. From the cost savings listed in Table 1, the simple paybacks for XPS case are 16.4 years in Phoenix and 18.9 years in Baltimore.

For the TAC case, cost of foil-faced XPS is not readily available. Thus, an installed cost of $\$ 1.11 / \mathrm{ft}^{2}$ of $0.5^{\prime \prime}$ foil-faced polyiso are used. ${ }^{7}$ The total cost of retrofitting with three layers of polyiso is $\$ 6436$ and resulting payback periods are 25-9-27.5 years. It is noted that the aforementioned cost of polyiso is with foil on both faces; for the TAC, foil facing is only needed on one surface. Conversely, the cost of heat sink and source and operating cost will need to be considered to get more accurate payback estimates.

In addition to energy savings, TACs can also reduce peak electricity demand. Benefit of the reduction in peak electricity demand is not quantified in this study. This project is continuing in FY19 and possibly beyond. The project team will pursue optimization of TAC designs and strategies to increase the overall efficacy of the TAC systems, analyze energy savings and peak load reduction potential under different climate conditions, perform more rigorous economic analysis and investigate cost reduction measures.

\section{ACKNOWLEDGEMENT}

This manuscript has been authored by UT-Battelle, LLC, under Contract No. DE-AC05-000R22725 with the US Department of Energy. We gratefully acknowledge the funding support from Mr. Sven Mumme of the DOE's Building Technologies Office.

\section{REFERENCES}

1. K. Biswas and S. Shrestha. Technical and economic feasibility of anisotropic thermal management in building envelopes: A high-level numerical simulation study. ORNL/TM-2017/286, September 2017.

${ }^{6} \mathrm{http}: / / \mathrm{www} . \mathrm{nrel} . \mathrm{gov} / \mathrm{ap} / \mathrm{retrofits} / \mathrm{measures} . \mathrm{cfm} ? \mathrm{gld}=12 \& \mathrm{ctld}=410$

7 https://www.rsmeansonline.com/ 